\title{
Leadership Styles and Organisational Structure
}

\author{
Renier Steyn \\ Graduate School of Business Leadership, University of South Africa, \\ P.O. Box 392, Pretoria, 0003, South Africa. \\ E-mail: steynr@unisa.ac.za
}

Received: July 2, 2020 Accepted: July 20, 2020 Online published: July 26, 2020

doi:10.5296/ijhrs.v10i3.17295 URL: https://doi.org/10.5296/ijhrs.v10i3.17295

\begin{abstract}
Background: In the call for papers to the 18th International Studying Leadership Conference, the organisers present an argument that leadership is place-bound, and ask a very specific question: "Why does leadership style vary from place-to-place?" This article presents a response to the assumption implicit in this question and also answers the following question: "Does leadership style differ from place-to-place?" Theoretical underpinning: The link between leadership styles and organisational structure is implicit, given general systems theory (Von Bertalanffy, 1968). Leadership styles are presented in terms of Pearce, Sims Jr, Cox, Ball, Schnell, Smith and Treviño's (2003) typology of leadership styles and organisational structure typology, as specified by Mintzberg's (1992, 2009). Aim: The aim of this article is to present empirical information on the relationship between leadership styles and the organisational structures within which they manifest. This will provide an answer to the question, "Does leadership style differ from place-to-place?" Ultimately, this may contribute to aligning leaders to organisations. Setting: Data was collected from nine medium-to-large sized organisations operating within an urban environment in South Africa. Method: A cross-sectional survey design was used to collect quantitative data on leadership styles. Data on organisational structure was collected by subject matter experts. Analyses of variance were performed to test hypotheses that leadership styles are equal across organisational structures. Results: The measures of leadership styles showed acceptable levels of reliability and evidence of factorial validity. Statistically significant differences between the leadership styles were detected for transformational, transactional, and directive leadership, but not for empowering leadership. Only for directive leadership were these differences practically significant. These results were linked to organisational structure data. Discussion: Although it is not difficult to create hypotheses linking leadership styles with organisational structure, it was difficult to find these differences in the data and to find cases where these hypotheses held across all the organisations. Practical significant differences occurred for directive leadership only. Conclusion: Before asking, "Why does leadership
\end{abstract}


style vary from place-to-place?" this research asked, "Does leadership style differ from place-to-place?" Given this particular sample, and the manner in which place was defined, place does not seem to dictate the leadership style present in a particular environment.

Keywords: leadership styles, organisational structure, Mintzberg, general systems theory

\section{Introduction}

In the call for papers to the 18th International Studying Leadership Conference, the organisers present an argument that leadership place-bound, and ask a very specific question: "Why does leadership style vary from place-to-place?" (Edwards, 2019: 2). The assumption underpinning this call may be intuitively, and even theoretically sustainable, however it requires a thorough empirical investigation. A critical rationalism approach was thus followed, where the researcher starts off with a biased idea ("Leadership style varies from place-to-place"), and then compares this idea against reality to determine if it is right or wrong (Higgs \& Smith, 2006). This article presents a response to the assumption implicit in this question and also answers the following question: "Does leadership style differ from place-to-place?"

The assumption linking leadership styles to organisational structure could, at a meta-theoretical level, be associated with general systems theory. This theory emphasises the "wholeness" of organisms which work as a complete unit, rather than as individual parts (Von Bertalanffy, 1968), and where the outputs generate the inputs that are required to maintain the system (Katz \& Kahn, 1966). The theory sanctions a notion that individuals influence the environment (organisational structure) and that a feedback loop from the environment influences the individuals (leadership styles) (see Kast \& Rosenzweig, 1972; Von Bertalanffy, 1968). The theory can be seen as deterministic (Teece, 2018), as the elements respond to each other and, in this study, this is reflected in the reciprocity between leadership styles and organisational structure.

Several other theories are important within the context of this research. While trait theories of leadership suggest that personality traits dictate leadership behaviour (Lord, de Vader \& Alliger, 1986), situational theories suggest that leaders adjust to their environment (employees) (Blanchard, Zigarmi \& Nelson, 1993). Even more appropriate for this research are the person-organisation-fit (P-O fit) theories (French, Rodgers \& Cobb, 1974), which suggest that compatibility between employees and organisations when they share fundamental characteristics. This, then, directly leads to the even more pertinent theory of attraction-selection-attrition (Schneider, Goldstein \& Smith, 2006), which suggests that individuals are attracted to and seek to work for organisations where they perceive high levels of P-O fit (Gregory, Albritton, \& Osmonbekov, 2010). Organisations do, however, get rid of misfits, as is well explained in the theories of reciprocity (Göbel, Vogel \& Weber, 2013; Molm, 2010).

Given the aforementioned theoretical link, and the call for conference already alluded to, the aim of this article is to present empirical findings on the relationship between leadership styles and the organisational structures within which they manifest. This will provide an 
answer to the question, "Does leadership style differ from place-to-place?" Ultimately, it may also contribute to aligning leaders, which manifest certain preferred styles, to organisations in which these styles are predominant, or more accurately stated, organisations where the leadership styles are supported by a complimenting structure.

Before commencing with the empirical study, the leadership styles and organisational structure will be briefly discussed. Leadership styles are conceptualised in accordance with Pearce et al.'s (2003) leadership typology, encompassing four styles, namely transformational, transactional, empowering and directive leadership. Organisational structure is presented in accordance with two organisational structure differentiators specified by Mintzberg's (1992, 2009), namely the prime coordinating mechanisms and the type of decentralisation they employed.

\section{Literature Review}

"Leadership has diverse meanings and connotations and has been described variously" (Penceliah, 2011: 46). As such, definitions of leadership is abandon, and, as early as 1997, it is stated that "there are hundreds of definitions of leadership" (Adler, 1997: 174). Yukl (1999) states that the diversity of leadership definitions stems from evidence on diverse topics such as individual leaders' traits, behaviours, interactions; different role connections; leaders' influence on followers and their perceptions; leaders' impact on tasks and objectives; and also their ability to influence organisational culture. Despite the complexity and varied conceptualisations of leadership, certain elements appear to be focussed upon across definitions, namely that leadership is a process which involves influence, takes place within groups, and which targets shared objectives (Northouse, 2013). Winston and Patterson (2006: 7) provide a potent and comprehensive working definition of leadership, stating that leadership involves one or more people "who selects, equips, trains, and influences one or more follower(s) who have diverse gifts, abilities, and skills and focuses the follower(s) to the organization's mission and objectives causing the follower(s) to willingly and enthusiastically expend spiritual, emotional, and physical energy in a concerted coordinated effort to achieve the organizational mission and objectives".

Leadership theory evolved from a focus on the characteristics of leaders (Trait theories, 1920s), to highlighting leader behaviours (Style theories, 1950s), emphasising the situation or context in which leadership occurred (Contingency theories, 1960s), leadership as a function of charisma (Charismatic theory, 1970s), which was later amalgamated into transformational leadership, which entailed a range of qualities over and above charisma (Neo charismatic theory, 1980's). In the late 1990s, leadership was explored in terms of strategic decision-taking and change management (Strategic leadership and Change leadership, 1990s) (Pendleton \& Furnham, 2016). Despite the changes reported in the late 1990's, transformational leadership (Clark \& Waldron, 2016; Meuser, Gardner, Dinh, Hu, Liden \& Lord, 2016), as well as its predecessor, charismatic leadership (Day \& Antonakis, 2012; Sims, Faraj, \& Yun, 2009), receives most of the focus in leadership research. Along with the transformational leadership, the transformational / transactional leadership typology (Avolio \& Bass, 1995) attracted a great deal of research interest (Avolio, Walumbwa \& Weber, 2009; 
Yukl, 1999).

Leadership styles, for the purpose of this research, are presented in line with the leadership typology of Pearce at al. (2003). According to this typology, four theoretical behavioural types are defined, namely transformational, transactional, empowering and directive leadership. It is seen as an approach encompassing the present and past theorisations of leadership (Sims et al., 2009; Yun, Cox, Sims \& Salam, 2007), incorporating the less distinct conglomerations of various leadership behaviours (i.e. transformational and transactional leadership) with discrete and opposing leadership elements (i.e. empowering and directive leadership) (Hmieleski \& Ensley, 2007). A short description of each of these leadership styles is presented below:

- Empowering leadership: Empowering leadership involves "sharing power with subordinates and raising their level of autonomy and responsibility, and it manifests through specific behaviours such as encouraging subordinates to express opinions and ideas, promoting collaborative decision making, and supporting information sharing and teamwork" (Lorinkova, Pearsall \& Sims, 2013: 573). Empowering leadership is viewed as consisting of four elements, namely emphasising the importance of the work to be done, communicating confidence in employees' ability to perform at a decision-making level, nurturing involvement in decision making, and permitting autonomy from bureaucratic restrictions (Ahearne, Mathieu \& Rapp, 2005). The behaviours characteristic of this leadership style are therefore directed at employee development (Burke et al., 2006), specifically self-management (Mohamed, 2016). Employees are encouraging and assisted to lead and manage themselves (Tuckey, Bakker \& Dollard, 2012).

- Directive leadership: Directive leadership is typified by providing employees with direction through the delivery of clearly laid out duties and responsibilities (Zhu, Kraut \& Kittur, 2013). The leaders take charge of clarifying work requirements, scheduling tasks, stipulating the rules, protocols and processes to be followed, setting communication structures, and ultimately assessing delivery (Mehta, Dubinsky \& Anderson, 2003). The clarity of direction and the clear goals set promote employee engagement and allows organisations to escape inertia flowing from factionalism (Fisher, 2016). This leadership style is premised upon positional or legitimate power, and is favoured in high power distance cultures (Houghton \& Yoho, 2005; Mustafa \& Lines, 2016). Muczyk and Reimann (1987) distinguish between the "directive autocrat, a leader who individually takes decisions and who closely oversees consequent employee activities, and the "directive democrat", who involves employees in decision making, and then strictly monitors the employee's performance of their tasks.

- Transformational leadership: This widely researched leadership style advances the optimal performance of employees through encouraging them to align their efforts and ambitions to those of the leader's vision for the organisation (Avolio et al., 2009). This leadership type is incorporative of the charismatic style (Sims et al., 2009), and entails advancing the leader's allure and trust in his/her ideas (Tuckey et al., 2012). The transformational leader assures that employees pursue collective interests rather than only 
personal objectives (Inspirational motivation), assists employees to take charge of their own development (Individualised consideration), and facilitates the discovery of new mechanisms to solve problems (Intellectual stimulation), which ultimately increases the motivation of employees to perform optimally (Idealised influence) (Bass, 1998; To, Tse \& Ashkanasy, 2015).

- Transactional leadership: Transactions (clearly demarcated) between a leader and subordinates are fundamental to transactional leadership (Avolio \& Bass, 1995; Rowold, 2011). The leader outlines how particular efforts will be rewarded and the level of motivation of the employees is directed by these reward mechanisms (Pearce \& Sims, 2002). The leader is dominant in this exchange, and seldom contemplates employee needs directly (Avolio \& Bass, 1995). Furthermore, transactional leadership is conceptualised as involving two behavioural components, namely contingent reward, which is the process of setting goals and rewarding employees for meeting these expectations (as mentioned above), and management-by-exception, where the leader does not interfere with the employee's actions unless substantial problems are experienced and the employee cannot deliver the results agreed upon (Bono \& Judge, 2004). In essence, transactional leadership is a style of leadership that focuses on employee self-interest and motivates employees though rewards (Golla \& Johnson, 2013).

The central question in this article is whether certain leadership styles are predominant in certain organisational settings. Before answering this question, the idea of "organisational settings" needs to be typified. Mintzberg's $(1979,1993)$ typologies of organisational structure are very well respected and researched (Lunenburg, 2012; O'Neill, Beauvais, \& Scholl, 2016).

Mintzberg (1992, 2009) stated that (a) organisation structure configuration can be differentiated focusing on three elements, namely (b) the key decision makers, (c) the mechanism used coordinate activities, and (d) how decentralisation occurs. The elements central to Mintzberg's organisational structural configuration are the prime coordinating mechanism, the key part of the organisation, and the type of decentralisation which occurs (Mintzberg, 1979, 1993). These are introduced below, heavily borrowing from the work of Fred C. Lunenburg (Lunenburg, 2012).

- Five structural configurations (a): Simple structure (loose structure, typically driven by founders or entrepreneurial-minded leaders, empowered by energy and enthusiasm, but limited underdeveloped management processes), machine bureaucracy (typically found in large organisations with extensive rules and procedures, allowing for consistency and longevity, but hampered by slow reaction times and in embracing innovation), professional bureaucracy (employing a large number of professional or technically skilled workers, allowing for more autonomy of employees and decentralised decision making, but still hampered by bureaucratic red tape), divisionalised form (typical in large organisations with several business units and product lines, where businesses and products are divided to promote specific management of each division, maintaining central control), and adhocracy (where decision making is decentralised, and empowered leaders are allowed to make 
judgments, allowing for operational innovation, but being at risk of leadership conflict and uncertainty over authority).

- Five key parts of the organisation (b): Strategic apex (top management and its support staff), operative core (those involved in operations and operational processes), middle line or middle-level management, support staff (those outside of operating workflow and who support operations), and the technostructure (the designers' systems and processes).

- Five prime coordinating mechanisms (c): Direct supervision (where seniors oversee juniors, tell them what to do, and take responsibility for the quality of the work), standardisation of work (where work processes are specified, carrying out of interrelated tasks, typically the outcome of time-and-motion studies), standardisation of skills (normally involving specialised or professional responsibilities, standardisation of skills or knowledge required for the job, with employees acting spontaneously to changes in the environment), mutual adjustment (when coordination occurs through informal communication and consistent feedback loops between all parties involved) and, lastly standardisation of output (where results or outcomes are specified, and where the product delivered is essential to coordination, requiring each role-player to meet performance targets or the specifications decided upon).

- Three type of decentralisation (d): Vertical decentralisation (where decision-making power is formally "delegated" down the chain of line authority), horizontal decentralisation (where decision-making is informal, outside the chain of line authority, based on interpersonal trust), and selective decentralisation (where decision-making power is delegated to "independent" units within the organisation, focusing on their own operations, which are aligned to operational strategy).

The five structural configurations (a) are associated with the three basic dimensions (b, c and d), and in the following manner (Lunenburg, 2012):

- Simple structure follows where direct supervision is the prime coordinating mechanism, the strategic apex is the key part of organisation, and where vertical and horizontal centralisation is predominant.

- Machine bureaucracy structure follows where standardisation of work processes is the prime coordinating mechanism, the technostructure is the key part of organisation, and where limited horizontal decentralisation is common.

- Professional bureaucracy structure follows where standardisation of skills is the prime coordinating mechanism, the operating core is the key part of organisation, and where vertical and horizontal decentralisation occurs most.

- Divisionalised structure follows where standardisation of outputs is the prime coordinating mechanism, the middle line is the key part of organisation, and where limited vertical decentralisation is dominant.

- Adhocracy structure follows where mutual adjustment is the prime coordinating mechanism, the support staff is the key part of organisation, and where selective 
decentralisation transpires.

The link between leadership styles and organisational structure, as stated in the background section of the paper, is largely embedded in P-O fit (French et al., 1974) and attraction-selection-attrition theory (Schneider et al., 2006). Given these theorisations, and the literature presented, the following hypotheses were formulated:

$\mathrm{H} 1_{0}$ : Leadership styles are similar, irrespective of the primary coordinating system (and organisational structure).

$\mathrm{H} 1_{\mathrm{a} 1}$ : Directive leadership would be more common in organisations where the coordination occurs through direct supervision (with a simple organisational structure).

$\mathrm{H}_{\mathrm{a} 2}$ : Transactional leadership would be more common in organisations where the coordination occurs through standardisation of work (with a machine bureaucracy structure).

$\mathrm{H} 1_{\mathrm{a} 3}$ : Transformational leadership would be more common in organisations where the coordination occurs through standardisation of skills (with a professional bureaucracy structure).

$\mathrm{H}_{\mathrm{a} 4}$ : Empowering leadership would be more common in organisations where the coordination occurs through mutual adjustment (with an adhocracy structure).

With regard to decentralisation, the following hypotheses were set:

$\mathrm{H} 2_{0}$ : Leadership styles are similar, irrespective of the way decentralisation occurs.

$\mathrm{H} 2_{\mathrm{a} 1}$ : Directive leadership would be more common where vertical decentralisation occurs.

$\mathrm{H} 2_{\mathrm{a} 2}$ : Transactional leadership would be more common where vertical decentralisation occurs.

$\mathrm{H} 2_{\mathrm{a} 3}$ : Transformational leadership would be more common where horizontal decentralisation occurs.

$\mathrm{H} 2_{\mathrm{a} 4}$ : Empowering leadership would be more common in organisations where horizontal decentralisation occurs.

Rejecting the null hypotheses will suggest that leadership style and organisational structure are linked. It is important to note that the link here is not necessarily directional: Just as leadership style may influence structure, structure may just as well influence leadership style. This reciprocal proposition is defensible, given general systems theory, and the latter part of the proposition (structure influencing behaviour) is soundly defensible, given $\mathrm{P}-\mathrm{O}$ fit and the attraction-selection-attrition theory.

\section{Method}

\subsection{Research Design}

A cross-sectional survey design was used to collect quantitative data on the leadership styles of managers. Data, mostly categorical data, on organisational structure was collected by subject matter experts, after they had familiarised themselves with the functioning of the organisation. 


\subsection{Setting}

Data was collected in nine medium-to-large sized organisations, from respondents who were able to report on their leaders' leadership styles. The selected organisations were all in South Africa and operating within an urban environment. The organisations differed in both their prime coordinating mechanisms and in the types of decentralisation they employed.

\subsection{Data Collection}

Data on leadership styles, in line with Pearce et al.'s (2003) conceptualisation, was collected using instruments developed by Podsakoff, MacKenzie, Moorman, and Fetter (1990), Pearce and Sims (2002) and Hwang, Quast, Center, Chung, Hahn, and Wohkittel (2015) and Ahearne et al. (2005). All these instruments have a track record of acceptable reliability and validity. Data on organisational structure were generated using Lunenburg's (2012) descriptions of Mintzberg's typologies. As stated previously, data on organisational structure were collected by subject matter experts.

\subsection{Statistical Analyses}

Basic descriptive statistics of the sample and the organisations surveyed were calculated and presented. Then, the reliability information on the different measures of leadership was provided. The Cronbach alpha coefficients were calculated, with values ranging from .70 to .95 deemed as acceptable (Tavakol \& Dennick, 2011). The factorial validity of the leadership measures was evaluated, following the performance of an exploratory factor analysis, by dividing the number of items (in the instrument) by the number of items that loaded dominantly (with no dual loadings) as expected. A coefficient higher than .90 was deemed indicative of factorial validity. Then, the hypotheses on differences between leadership styles across organisations were tested, based on the observed prime coordinating mechanisms and the type of decentralisation employed in the organisations. Analyses of variance (ANOVA) were performed to test hypotheses that leadership styles are equal across organisational structures, and the Scheffe post-hoc test was applied to specify which pairs of organisations differ from each other. The null hypotheses of all groups being equal were rejected only where the ANOVA results were significant $(\mathrm{p}<.05$ for the F-statistic). Alternative hypotheses were supported given that the post-hoc test-statistics were significant, with $\mathrm{p}<.05$. Furthermore, due to the simplicity and clarity of the Cohen d-value $\left(\left(\mathrm{Mean}_{\mathrm{A}}-\right.\right.$ Mean $_{B}$ ) / Pooled standard deviation ${ }_{A B}$ ), these were also calculated. Cohen (1988) indicates that d-values equal to .2 represent a small effect, .5 a medium effect and .8 a large effect. These cut-off scores were also used in this research

\section{Results}

Data was collected from a total of 620 participants across six organisations. Descriptive data was collected regarding the participants' gender, race, schooling, role, post level, age and tenure. The results are presented below. 
Table 1. Gender and race

\begin{tabular}{llcc}
\hline \multirow{3}{*}{ Gender } & & Frequency & Percentage \\
\cline { 3 - 4 } & Male & 313 & 50.5 \\
& Female & 301 & 48.5 \\
\multirow{3}{*}{ Race } & Other & 3 & .5 \\
& Missing & 3 & .5 \\
\cline { 2 - 4 } & Asian & 28 & 4.5 \\
& Black & 440 & 71.0 \\
& Coloured & 42 & 6.8 \\
& White & 103 & 16.6 \\
& Missing & 7 & 1.1 \\
\hline
\end{tabular}

The majority of the participants were male, 50.5\%. The participants represented all race/ethnic groups, with the majority being black, $71.0 \%$. Data on schooling, role and post level is presented below.

Table 2. Schooling, role and post levels

\begin{tabular}{llcc}
\hline \multirow{3}{*}{ Schooling } & & Frequency & Percentage \\
\cline { 3 - 4 } & $<12$ years & 19 & 3.1 \\
& 12 years & 138 & 22.3 \\
& Degree & 203 & 32.7 \\
\multirow{5}{*}{ Role } & Degree+ & 254 & 41.0 \\
& Missing & 6 & 1.0 \\
\cline { 2 - 4 } Post level & Core Business & 299 & 48.2 \\
& Support staff & 311 & 50.2 \\
& Missing & 10 & 1.6 \\
\cline { 2 - 4 } & Unskilled & 22 & 3.5 \\
& Semi-skilled & 134 & 21.6 \\
& Junior Management & 210 & 33.9 \\
& Middle Management & 197 & 31.8 \\
& Senior Management & 45 & 7.3 \\
& Missing & 12 & 1.9 \\
\hline
\end{tabular}

In terms of schooling, the majority of the participants reported having a higher degree or diploma, $41.0 \%$. In response to their role in the organisation, whether in support services or part of the core business, a small majority, 50.2\%, indicated that they were part of support services. With regard to post level, the majority of participants responded that they were part of junior management, $33.9 \%$, with middle management following closely, $31.8 \%$.

The mean age of the respondents is 37.81 years old with a standard deviation of 8.841 years (Range: 21 - 64). With regard to tenure, the mean tenure is 6.59 years with a standard deviation of 5.848 years (Range: $1-41$ ).

Information on organisational structure was gathered in respect of many aspects which could be informative regarding Mintzberg's organisational configurations. 
Table 3. Organisational structure

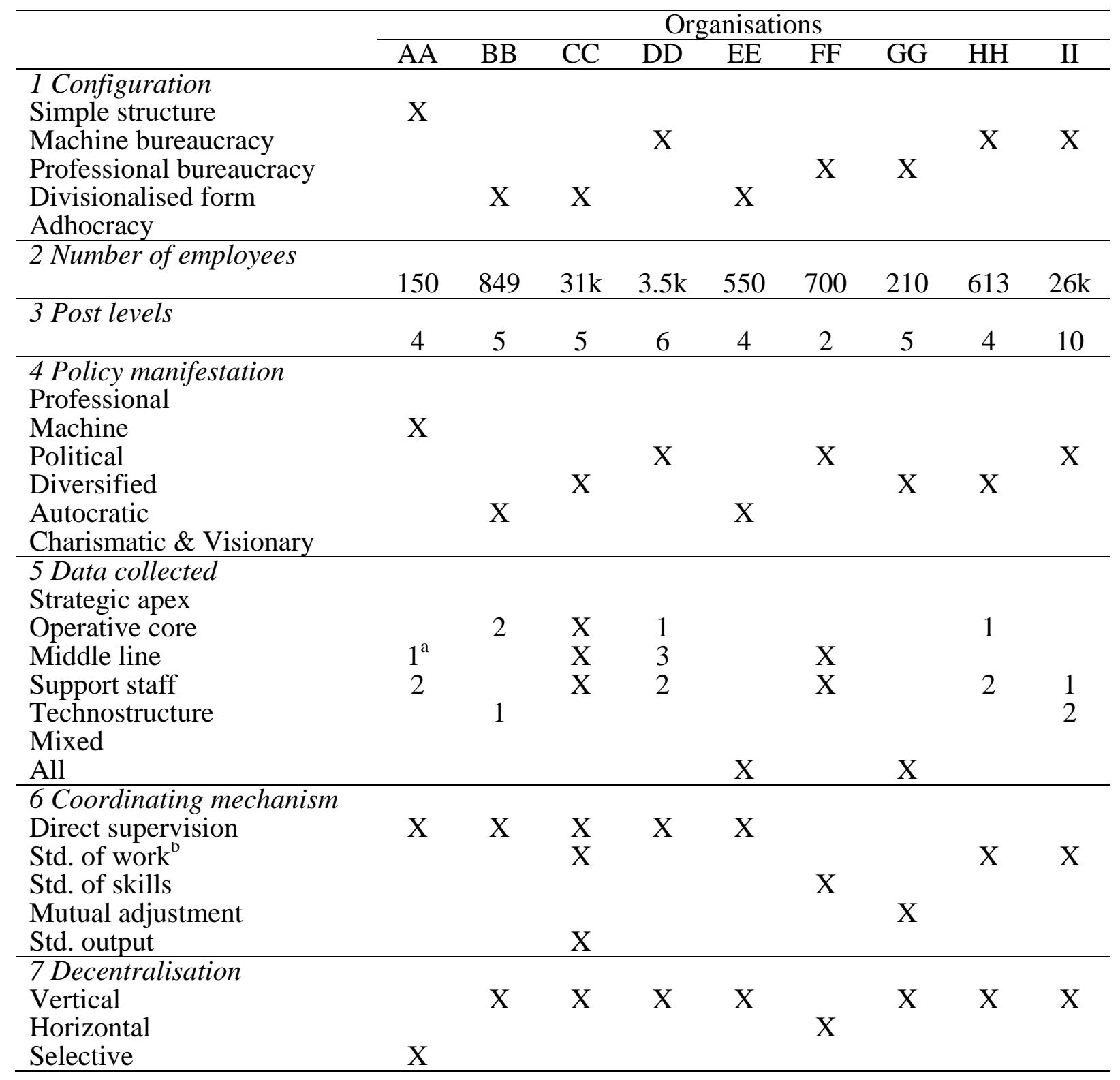

a The primary source of data collected is indicated by " 1 ", and the secondary source by " 2 ".

${ }^{\mathrm{b}}$ The abbreviation Std. refers to standardisation.

From Table 3 we can observe that the organisations were diverse, and particularly when considering the columns, it was clear that no organisation matched any other. Comparisons, or finding differences between organisations would thus be difficult.

\subsection{Reliability}

The Cronbach alpha coefficients for all the instruments were satisfactory, with directive leadership (Hwang et al., 2015 (four items); Pearce \& Sims, 2002 (six items)) $\alpha=.889$, transactional leadership (Podsakoff et al., 1990 (5 items)) $\alpha=.957$, transformational leadership (Podsakoff et al., 1990 (6 items)) $\alpha=.924$, and empowering leadership (Ahearne et al., 2005 (10 items)) $\alpha=.922$. 


\subsection{Validity}

The factorial validity of the transactional-transformational leadership questionnaire was exceptional (Podsakoff et al., 1990 (4 + 6 items)), with all loadings as per leadership style and with no significant cross loadings. The two factors declared $78.70 \%$ of the variance in the data. Regarding empowering leadership (Ahearne et al., 2005 (10 items)), all items loaded on a single factor, with the lowest loading .622 and the highest .849 . In total, the single component was responsible for $59.65 \%$ of the variance. This also points to factorial validity. Lastly, concerning directive leadership directive leadership (Hwang et al., 2015 (four items); Pearce \& Sims, 2002 (six items)), the first four and the last six items loaded as per the conceptualisation of the developers of instrument, and there were no cross loadings. In total, $70.52 \%$ of the variance in the items was explained. Although theoretically perfect, these results (negatively) indicate that the two conceptualisations of directive leadership are distinct, but perhaps more importantly (positively), coherent conceptualisations. In general, the questionnaires used seem to support factorial validity.

\subsection{Differences Between Groups and Testing of Hypotheses}

The descriptive statistics, as per measurement scale of leadership style per organisation, are reflected below.

Table 4. Mean scores on leadership style per organisation

\begin{tabular}{lcccccccc}
\hline & \multicolumn{7}{c}{ Leadership style } \\
\cline { 2 - 9 } & \multicolumn{2}{c}{ Transactional } & \multicolumn{2}{c}{ Directive } & Transformational & \multicolumn{2}{c}{ Empowering } \\
\cline { 2 - 10 } Organisation & Mean & Dev. & Mean & Dev. & Mean & Dev. & Mean & Dev. \\
\hline AA & 2.170 & 1.318 & 2.368 & .855 & 2.566 & 1.593 & 2.898 & 1.421 \\
BB & 2.360 & 1.257 & 2.585 & .640 & 2.180 & 1.247 & 2.662 & 1.338 \\
CC & 2.810 & 1.821 & 2.433 & .827 & 2.704 & 1.671 & 2.649 & 1.402 \\
DD & 2.851 & 1.980 & 2.590 & .968 & 2.801 & 1.787 & 2.821 & 1.644 \\
EE & 2.507 & 1.525 & 2.567 & .814 & 2.647 & 1.534 & 2.732 & 1.441 \\
FF & 2.357 & 1.665 & 1.978 & .714 & 2.266 & 1.393 & 2.145 & 1.012 \\
GG & 2.384 & 1.726 & 2.359 & .849 & 2.695 & 1.646 & 2.843 & 1.288 \\
HH & 2.507 & 1.627 & 2.432 & .811 & 2.552 & 1.476 & 2.552 & 1.411 \\
II & 3.057 & 1.620 & 2.777 & .878 & 3.141 & 1.695 & 2.762 & 1.150 \\
Total & 2.592 & 1.689 & 2.470 & .860 & 2.640 & 1.608 & 2.693 & 1.401 \\
\hline
\end{tabular}

It is important to note in Table 4 that the scale for directive leadership ranged between 1 and 5, while the other scales ranged between 1 and 7. This explains the lower standard deviation values of the directive leadership scale. Given that the middle score on a 5-point scale is 3, and on a 7-point scale 4, the scores on leadership styles across the organisations are low. This suggests that employees experience low levels of leadership behaviours.

Considering the scores across columns, an ANOVA was performed to test whether means differed across organisations. The results of the analyses are presented below. 
Table 5. ANOVA, differences between groups regarding different leadership styles

\begin{tabular}{llrrrrr}
\hline Leadership style & & $\begin{array}{c}\text { Sum of } \\
\text { Squares }\end{array}$ & Df & $\begin{array}{c}\text { Mean } \\
\text { Square }\end{array}$ & F & Sig. \\
Transactional & Between Groups & 45.839 & 8 & 5.730 & 2.034 & .040 \\
& Within Groups & 1721.157 & 611 & 2.817 & & \\
\multirow{2}{*}{ Transformational } & Total & 1766.996 & 619 & & & \\
\cline { 2 - 7 } & Between Groups & 40.909 & 8 & 5.114 & 2.003 & .044 \\
& Within Groups & 1560.253 & 611 & 2.554 & & \\
Directive & Total & 1601.162 & 619 & & & \\
\cline { 2 - 7 } Empowering & Between Groups & 25.023 & 8 & 3.128 & 4.410 & $<.001$ \\
& Within Groups & 433.391 & 611 & .709 & & \\
& Total & 458.414 & 619 & & & .104 \\
& Between Groups & 25.949 & 8 & 3.244 & 1.665 & \\
& Within Groups & 1190.017 & 611 & 1.948 & & \\
\hline
\end{tabular}

Differences between the leadership styles across organisations were detected for transformational $(\mathrm{F}(8,661)=2.03, \mathrm{p}=.040)$, transactional $(\mathrm{F}(8,661)=2.00, \mathrm{p}=.044)$, and directive leadership $(\mathrm{F}(8,661)=4.41, \mathrm{p}<.001)$, but not for empowering leadership $(\mathrm{F}(8,661)$ $=1.665, \mathrm{p}=.104)$. Given the statistics presented, it seems that differences across organisations are particularly prevalent with regard to directive leadership.

The hypothesis that leadership styles are similar across organisations (" $\mathrm{H} 1_{0}$ : Leadership styles are similar ....") should thus be rejected. The alternative hypotheses (“ ... given certain structural considerations.") remains unanswered until the organisations which differ significantly are exposed and the structural characteristics studied. To deal with specific between-organisation differences, the results of the Scheffe post-hoc tests were relevant. These outputs are extensive and therefore impossible to present here. However, the results from the Scheffe post-hoc test revealed significant differences between pairs of groups for directive leadership only, and this was between groups FF and DD (mean of $1.978<2.590$, mean difference $=.611, \mathrm{p}=.006$, Cohen's $\mathrm{d}=.710$ ), and groups FF and II (mean of $1.978<$ 2.777 , mean difference $=.798, p=.001$, Cohen's $d=.928$ ). Two homogeneous subsets were found for directive leadership and these are presented below.

Table 6. Homogeneous subsets for mean scores on directive leadership

\begin{tabular}{lcc}
\hline & \multicolumn{2}{c}{ Subset for alpha $=0.05$} \\
\cline { 2 - 3 } Group & Subset 1 & Subset 2 \\
\hline FF & 1.978 & - \\
GG & 2.359 & 2.359 \\
AA & 2.368 & 2.368 \\
HH & 2.432 & 2.432 \\
CC & 2.433 & 2.433 \\
EE & - & 2.567 \\
BB & - & 2.585 \\
DD & - & 2.590 \\
II & - & 2.777 \\
Sig. & .313 & .441 \\
\hline
\end{tabular}


At this stage, it is important to note that differences were found only for directive leadership and only between three groups. Leadership style, even given the results presented in Table 5, did not differ much across organisations, and did so significantly only in respect of directive leadership.

To test hypotheses on the differences of leadership styles across groups, a review of the set (alternative) hypotheses pertaining only to directive leadership is sufficient:

$\mathrm{H} 1_{\mathrm{a} 1}$ : Directive leadership would be more common in organisations where the coordination occurs through direct supervision (with a simple organisational structure).

$\mathrm{H} 2_{\mathrm{a} 1}$ : Directive leadership would be more common in organisations where vertical decentralisation occurs.

Returning to Table 3, where organisation characteristics are displayed, now becomes relevant for the interpretation of these findings. DD scored higher than FF on directive leadership, something which was expected as DD had direct supervision and FF standardisation of skills (see Table 3). Though not directly hypostasized, the fact that II also scored higher than FF may also be explainable, given that standardisation of work is much more aligned to direct supervision than is standardisation of skills. Both detected differences are in support of $\mathrm{H} 1_{\mathrm{a} 1}$.

With regard to $\mathrm{H} 2{ }_{\mathrm{a} 1}$, it is interesting to note from Table 3 that FF was the only organisation reporting horizontal decentralisation. The fact that AA and II reported vertical decentralisation supports the notion that organisations differ. These detected differences are in support of $\mathrm{H} 2_{\mathrm{a} 1}$.

\section{Discussion}

This research tried to answer the question: "Does leadership style differ from place-to-place?" In the attempt to answer the question, data was gathered from a group of South African employees reasonably representative of the local workforce. The instruments used were reputable, had excellent reliability, and showed acceptable factorial validity. Complete data was collected from 620 employees.

Leadership style data was collected following the typology of Pearce at al. (2003). Creating central statistics, and some inferential statistics on "other" leadership styles, answers Sharma and Kirkman's (2015) call for more research, Li, Liu, Han and Zhang's (2016) call to focus more on empowering leadership, and Kalaluhi's (2013) and Martin, Liao and Campbell's (2013) declaration that, within the organisational setting, very little attention is given to (the often practiced) directive leadership.

The data revealed relatively low scores on the different leadership styles. This may be worrying, as it seems that leaders does not engage with their subordinates. This is, however, not an aim of the study, but simply an interesting observation. The prevalence of leader-member exchange could also be a very interesting research topic.

The overarching null hypothesis set was that leadership styles and practices in different situations are similar, irrespective of the organisational structure. It was expected that this 
hypothesis should be rejected, and that alternative hypotheses would be considered, given systems theory, and particularly P-O fit and the attraction-selection-attrition theory, which will not permit/sustain/support behaviour (leadership) that does not fit the broader context (organisational structure). Applying the ANOVA test, statistically significant differences in the prevalence of leadership styles were found across transactional, transformational and directive leadership styles, though the empowering leadership style was excluded here (see Table 5 above). Employees (grouped together by their organisational affiliation) reported that, per organisation, statistically significant differences occurred in the levels of transactional, transformational and directive leadership which they experience. The difference seemed most prevalent when considering directive leadership. Directive leadership is clearly a top-down and power-distance orientated style (Lunenburg, 2012), which may be more observable, and frowned upon, in the democratic workplace (Cascio \& Aguinis, 2013) that we observe in the post-modern dispensation. Using the Scheffe post-hoc test to specify which pairs of organisations differ from each other, the only significant differences were detected within the previously mentioned directive leadership, where group FF scored significantly lower than group DD ( $\mathrm{p}=.006$, Cohen's $\mathrm{d}=.710)$ and where group II was higher than group FF ( $\mathrm{p}$ $=.001$, Cohen's $d=.928)$. Focusing only on these three organisations (FF, DD and II), and considering only directive leadership, the hypotheses set on how leadership styles and organisation structure align were authenticated. Leadership styles thus matched organisational structure in these cases. However, these are three organisations (out of the nine organisations considered) and one leadership style (out of four) is examined. This implies that in three of the possible 36 cases, hypotheses on leadership style and organisational structure were endorsed, which amounts to $8.3 \%$ of all possible cases. This suggests a low empirically supported acceptance rate for the leadership-organisational structure link. Although it was not difficult to create hypotheses about which leadership styles could be predominant within specific organisational structures, it was hard to find these differences materialising in the data. Also, even when detecting differences, and even if the differences were in line with what was hypothesised, the same hypotheses did not hold across all leadership styles and all the observed organisations.

\section{Conclusion}

Before asking "Why does leadership style vary from place-to-place?", this research asked, "Does leadership style differ from place-to-place?" Given this particular sample, and how place was defined, place does not seem to dictate the leadership style present in a particular environment. This article contributes to the debate on "Putting leadership in its place", as was the aim of the 18th International Studying Leadership Conference (Edwards, 2019: 2). Further research, particularly if data were to be obtained from more organisations, could be useful in advancing our understanding of how place influences behaviour, and vice versa.

\section{References}

Adler, N. J. (1997). Global leadership: Women leaders. Management International Review, 37(1), 171-196. 
Ahearne, M., Mathieu, J., \& Rapp, A. (2005). To empower or not to empower your sales force? An empirical examination of the influence of leadership empowerment behavior on customer satisfaction and performance. Journal of Applied Psychology, 90(5), 945-955.

Avolio, B. J., \& Bass, B. M. (1995). Individual consideration viewed at multiple levels of analysis: A multi-level framework for examining the diffusion of transformational leadership. The Leadership Quarterly, 6(2), 199-218.

Avolio, B. J., Walumbwa, F. O., \& Weber, T. J. (2009). Leadership: Current theories, research, and future directions. Annual Review of Psychology, 60, 421-449.

Bass, B. M. (1998). Transformational leadership: Industrial, military and educational impact. Mahwah, NJ: Lawrence Erlbaum Associates.

Blanchard, K. H., Zigarmi, D., \& Nelson, R. B. (1993). Situational Leadership ${ }^{\circledR}$ after 25 years: A retrospective. Journal of Leadership Studies, 1(1), 21-36.

Bono, J. E., \& Judge, T. A. (2004). Personality and transformational and transactional leadership: A meta-analysis. Journal of Applied Psychology, 89(5), 901-910.

Burke, C. S., Stagl, K. C., Klein, C., Goodwin, G. F., Salas, E., \& Halpin, S. M. (2006). What type of leadership behaviors are functional in teams? A meta-analysis. The Leadership Quarterly, 17(3), 288-307.

Cascio, W. F., \& Aguinis, H. (2013). Applied psychology in human resource management. Essex: Pearson.

Clark, K. D., \& Waldron, T. (2016). Predictors of leadership behavior in early career white-collar professionals: The roles of personal characteristics and career context. Journal of Leadership \& Organizational Studies, 23(1), 27-38.

Cohen, J. (1988). Statistical power analysis for behavioral sciences. Mahwah, NJ: Lawrence Erlbaum Associates.

Day, D. V., \& Antonakis, J. (2012). Leadership: Past, present, and future. In D. V. Day, \& J. Antonakis (Eds.), The nature of leadership (pp. 3-25). Thousand Oaks, CA: SAGE Publications.

Edwards, G. (2019). The 18th International Studying Leadership Conference. From: https://info.uwe.ac.uk/events/event.aspx?id=24096, Accessed: 30 August 2019

Fisher, J. (2016). The thoughtful leader: A model of integrative leadership. Toronto: Rotman-UTP.

French, J. R. P., Jr., Rodgers, W. L., \& Cobb, S. (1974). Adjustment as person-environment fit. In G. Coelho, D. Hamburg, \& J. Adams (Eds.), Coping and adaptation (pp. 316-333). New York: Basic Books

Göbel, M., Vogel, R., \& Weber, C. (2013). Management research on reciprocity: A review of the literature. Business Research, 6(1), 34-53. 
Golla, E., \& Johnson, R. (2013). The relationship between transformational and transactional leadership styles and innovation commitment and output at commercial software companies. The Business Review, Cambridge, 21(1), 337-343.

Gregory, B. T., Albritton, M. D., \& Osmonbekov, T. (2010). The mediating role of psychological empowerment on the relationships between $\mathrm{P}-\mathrm{O}$ fit, job satisfaction, and in-role performance. Journal of Business and Psychology, 25(4), 639-647.

Higgs, P., \& Smith, J. (2006). Rethinking truth (2nd ed.). Cape Town: Juta.

Hmieleski, K.M., \& Ensley, M.D. (2007). A contextual examination of new venture performance: Entrepreneur leadership behavior, top management team heterogeneity, and environmental dynamism. Journal of Organizational Behavior, 28(7), 865-889.

Houghton, J.D., \& Yoho, S.K. (2005). Toward a contingency model of leadership and psychological empowerment: When should self-leadership be encouraged? Journal of Leadership and Organizational Studies, 11(4), 65-83.

Hwang, S. J., Quast, L. N., Center, B. A., Chung, C. N., Hahn, H., \& Wohkittel, J. (2015). The impact of leadership behaviours on leaders' perceived job performance across cultures: Comparing the role of charismatic, directive, participative, and supportive leadership behaviours in the U.S and four Confucian Asian countries. Human Resource Development International, 18(3), 259-277.

Kalaluhi, S. (2013). Leadership in context: The moderating effect of follower need for autonomy on directive leadership style, empowering leadership style, and leader effectiveness in volunteer organizations. In Global Conference on Business and Finance Proceedings (pp. 139-143). Hilo, HI: The Institute for Business and Finance Research.

Kast, F. E., \& Rosenzweig, J. E. (1972). General systems theory: Applications for organization and management. Academy of Management Journal, 15, 447-465.

Katz, D., \& Kahn, R. L. (1966). The social psychology of organizations. Oxford: Wiley.

Li, M., Liu, W., Han, Y., \& Zhang, P. (2016). Linking empowering leadership and change-orientated organizational citizenship behavior: The role of thriving at work and autonomy orientation. Journal of Organizational Change Management, 29(5), 732-750.

Lord, R. G., de Vader, C. L., \& Alliger, G. M. (1986). A meta-analysis of the relation between personality traits and leadership perceptions: An application of validity generalization procedures. Journal of Applied Psychology, 71(3), 402-410. https://doi.org/10.1037/0021-9010.71.3.402

Lorinkova, N. M., Pearsall, M. J., \& Sims, H. P., Jr. (2013). Examining the differential longitudinal performance of directive versus empowering leadership in teams. Academy of Management Journal, 56(2), 573-596.

Lunenburg, F. C. (2012). Organizational structure: Mintzberg's framework. International Journal of Scholarly, Academic, Intellectual Diversity, 14(1), 1-8. 


\section{Macrothink}

International Journal of Human Resource Studies ISSN 2162-3058 2020, Vol. 10, No. 3

Martin, S. L., Liao, H., \& Campbell, E. M. (2013). Directive versus empowering leadership: A field experiment comparing impacts on task proficiency and proactivity. Academy of Management Journal, 56(5), 1372-1395.

Mehta, R., Dubinsky, A. J., \& Anderson, R. E. (2003). Leadership style, motivation and performance in international marketing channels. European Journal of Marketing, 37(1/2), $50-85$.

Meuser, J. D., Gardner, W. L., Dinh, J. E., Hu, J., Liden, R. C., \& Lord, R. G. (2016). A network analysis of leadership theory: The infancy of integration. Journal of Management, 42(5), 1374-1403.

Mintzberg, H. (1979). The structuring of organizations: A synthesis of the research. Englewood Cliffs, NJ: Prentice Hall.

Mintzberg, H. (1992). Structure in fives: Designing effective organizations. Upper Saddle River, NJ: Prentice Hall.

Mintzberg, H. (2009). Tracking strategies: Toward a general theory of strategy formation. New York, NY: Oxford University Press.

Mohamed, L. M. (2016). Assessing the effects of transformational leadership: A study on Egyptian hotel employees. Journal of Hospitality and Tourism Management, 27, 49-59.

Molm, L. D. (2010). The structure of reciprocity. Social Psychology Quarterly, 73(2), 119-131.

Muczyk, J. P., \& Reimann, B. C. (1987). The case for directive leadership. The Academy of Management Executive, 1(4), 301-311.

Mustafa, G., \& Lines, R. (2016). The emergence and effects of culturally congruent leadership: Current status and future developments. Entrepreneurial Business and Economics Review, 4(1), 161-180.

Northouse, P. G. (2013). Leadership: Theory and practice (6th ed.). Thousand Oaks, CA: SAGE Publications.

O'Neill, J. W., Beauvais, L. L., \& Scholl, R. W. (2016). The use of organizational culture and structure to guide strategic behavior: An information processing perspective. Journal of Behavioral and Applied Management, 2(2), 816.

Pearce, C. L., \& Sims, H. P., Jr. (2002). Vertical versus shared leadership as predictors of the effectiveness of change management teams: An examination of aversive, directive, transactional, transformational, and empowering leader behaviors. Group Dynamics: Theory, Research, and Practice, 6(2), 172-197.

Pearce, C. L., Sims, H. P., Jr., Cox, J. F., Ball, G., Schnell, E., Smith, K. A., \& Treviño, L. (2003). Transactors, transformers and beyond: A multi-method development of a theoretical typology of leadership. Journal of Management Development, 22(4), 273-307. 
Penceliah, Y. (2011). Leadership in a multicultural organisational context: Some perspectives. Africanus, 41(2), 46-59.

Pendleton, D., \& Furnham, A. (2016). Leadership: All you need to know (2nd ed.). London: Springer Nature.

Podsakoff, P. M., MacKenzie, S. B., Moorman, R., \& Fetter, R. (1990). The impact of transformational leader behaviors on employee trust, satisfaction, and organizational citizenship behaviors. Leadership Quarterly, 1(2), 107-142.

Rowold, J. (2011). Relationship between leadership behaviors and performance: The moderating role of a work team's level of age, gender, and cultural heterogeneity. Leadership \& Organization Development Journal, 32(6), 628-647.

Schneider, B., Goldstein, H. W., \& Smith, D. B. (2006). The ASA framework: An update. Personnel Psychology, 48(4), 747-773.

Sharma, P. N., \& Kirkman, B. L. (2015). Leveraging leaders: A literature review and future lines of inquiry for empowering leadership research. Group \& Organization Management, 40(2), 193-237.

Sims, H. P., Jr., Faraj, S., \& Yun, S. (2009). When should a leader be directive or empowering? How to develop your own situational theory of leadership. Business Horizons, 52(2), 149-158.

Tavakol, M., \& Dennick, R. (2011). Making sense of Cronbach's alpha. International Journal of Medical Education, 2, 53-55.

Teece, D. J. (2018). Dynamic capabilities as (workable) management systems theory. Journal of Management \& Organization, 3, 110. https://doi.org/10.1017/jmo.2017.75

To, M. L., Tse, H. H. M., \& Ashkanasy, N. M. (2015). A multilevel model of transformational leadership, affect, and creative process behavior in work teams. The Leadership Quarterly, 26(4), 543-556.

Tuckey, M. R., Bakker, A. B., \& Dollard, M. F. (2012). Empowering leaders optimize working conditions for engagement: A multilevel study. Journal of Occupational Health Psychology, 17(1), 15-27.

Von Bertalanffy, L. (1968). General system theory: Foundations, development, applications. New York, NY: George Braziller.

Winston, B. E., \& Patterson, K. (2006). An integrative definition of leadership. International Journal of Leadership Studies, 1(2), 6-66.

Yukl, G. (1999). An evaluation of conceptual weaknesses in transformational and charismatic leadership theories. The Leadership Quarterly, 10(2), 285-305. 


\section{Macrothink}

International Journal of Human Resource Studies

ISSN 2162-3058 2020, Vol. 10, No. 3

Yun, S., Cox, J., Sims, H. P., Jr., \& Salam, S. (2007). Leadership and teamwork: The effects of leadership and job satisfaction on team citizenship. International Journal of Leadership Studies, 2(3), 171-193.

Zhu, H., Kraut, R. E., \& Kittur, A. (2013). Effectiveness of shared leadership in Wikipedia. Human Factors, 55(6), 1021-1043.

\section{Copyright Disclaimer}

Copyright for this article is retained by the author(s), with first publication rights granted to the journal.

This is an open-access article distributed under the terms and conditions of the Creative Commons Attribution license (http://creativecommons.org/licenses/by/4.0/). 